\section{$\checkmark$ Research Square}

\title{
Adjunctive sepsis therapy with aminophylline (STAP): a randomized controlled trial
}

\section{Ruifang Zhang}

Zhengzhou University First Affiliated Hospital

Huan Liu

Zhengzhou University First Affiliated Hospital

\section{Dongmei Dai}

Kunming Medical University First Affilliated Hospital

\section{Xianfei Ding}

Zhengzhou University First Affiliated Hospital

\section{Dong Wang}

Zhengzhou University First Affiliated Hospital

\section{Yan Wang}

Zhengzhou University First Affiliated Hospital

\section{Xuexiu Shi}

Zhengzhou University First Affiliated Hospital

\section{Shuguang Zhang}

Zhengzhou University First Affiliated Hospital

\section{Xiaoguang Duan}

Zhengzhou University First Affiliated Hospital

\section{Haixu Wang}

Zhengzhou University First Affiliated Hospital

\section{Yonggang Luo}

Zhengzhou University First Affiliated Hospital

\section{Shaohua Liu}

Zhengzhou University First Affiliated Hospital

\section{Bing Han}

Zhengzhou University First Affiliated Hospital

\section{Xiaojuan Zhang}

Zhengzhou University First Affiliated Hospital

\section{Yu Fang}

Zhengzhou University First Affiliated Hospital

\section{Wangbin Xu}

Kunming Medical University First Affilliated Hospital

Tongwen Sun ( $\nabla$ suntongwen@163.com ) 


\section{Research}

Keywords: Aminophylline, mortality, randomized controlled trial, sepsis

Posted Date: April 13th, 2021

DOl: https://doi.org/10.21203/rs.3.rs-412805/v1

License: (c) (i) This work is licensed under a Creative Commons Attribution 4.0 International License. Read Full License 


\section{Abstract}

\section{Background}

Sepsis is a serious disease that is often caused by infection. Aminophylline has anti-asthma and antiinflammatory effects. We aimed to explore the safety and effect of aminophylline in sepsis.

\section{Methods}

We conducted a clinical randomized controlled trial involving 100 patients diagnosed with sepsis within 48 hours after ICU (intensive care unit) admission in two sites (First Affiliated Hospital of Zhengzhou University and First Affiliated Hospital of Kunming Medical University). All patients were randomized in a 1:1 ratio to receive standard therapy with or without aminophylline. The primary clinical outcome was allcause mortality at 28 days.

Results

From 27 September 2018 to 12 February 2020, we screened 277 septic patients and eventually enrolled 100 patients, with 50 assigned to the aminophylline group and 50 to the usual-care group. At 28 days, 7 of 50 patients $(14.0 \%)$ in the aminophylline group had died, compared with 16 of $50(32.0 \%)$ in the usualcare group $(P=0.032)$. Cox regression showed that the aminophylline group had a lower risk of death $(\mathrm{HR}=0.312,95 \% \mathrm{Cl}: 0.129-0.753)$. Compared with the usual-care group, patients in the aminophylline group had a longer survival time ( $P=0.039$ by the log-rank test). With the extension of the treatment time, the effect of aminophylline on the doses of vasopressors, oxygenation index, and SOFA score increased. There were no significant differences in total hospitalization days, ICU hospitalization days, and rates of serious adverse events (all $P>0.05$ ). No adverse events were observed in the trial.

\section{Conclusions}

Aminophylline as an adjunct therapy could significantly reduce the risk of death and prolong the survival time of patients with sepsis.

Trial registration

The trial was registered at the Chinese clinical trial registry (ChiCTR1800019173), 29 October 2018 retrospectively registered, http://www.chictr.org.cn/index.aspx

\section{Introduction}

Sepsis has been listed as a health priority by the World Health Organization ${ }^{1}$ due to its resultant mortality rate of $25-30 \%$ and its associated extent of medical resources use $e^{2-5}$. The primary treatment strategies include early recognition, source control, anti-infective use, fluid resuscitation, and other supportive treatments ${ }^{6,7}$, with advanced measures being no more effective. 
Theophylline is a bronchodilator that is commonly used in bronchial asthma and chronic obstructive pulmonary disease (COPD). The drug can reduce gene expression of cytokines TNF- $a$ and IL-8 by increasing enzyme HDAC2 activity to inhibit the molecular activity of transcription factor NF-KB P65 $5^{8-10}$. Concurrently, theophylline can increase the anti-inflammatory effect of glucocorticoids and improve glucocorticoid resistance in COPD patients ${ }^{10,11}$. Besides its effect on bronchiectasis, aminophylline also has anti-inflammatory effects. During an acute asthma attack, aminophylline acts as an antiinflammatory by inhibiting the influx of neutrophils and eosinophils into the airway ${ }^{12-14}$. In addition, aminophylline can stimulate respiration, enhance respiratory muscle contractions, improve pulmonary ventilation, and even improve tolerance to hypoxia without increasing oxygenation ${ }^{15,16}$. Given that the lung is the most common infection site in sepsis ${ }^{17-19}$, and respiratory system injury is common, aminophylline has certain application advantages when the lung is affected.

Aminophylline is a non-selective adenosine receptor antagonist that can block the purinergic signaling cascade of adenosine using aminophylline therapy to inhibit the tubuloglomerular feedback loop, preventing a decrease in glomerular filtration rate and urine output, thus play a possible benefit in renal protection $^{20}$.

Although aminophylline may potentially have an effect on sepsis, there is a lack of clinical evidence for this phenomenon. This study was the first clinical study to explore the therapeutic effect of aminophylline use in sepsis.

\section{Methods}

\section{Study design and oversight}

From 27 September 2018 to 12 February 2020, we conducted a pragmatic, randomized controlled trial in two sites (General ICU, the First Affiliated Hospital of Zhengzhou University, and the Critical Care Department, First Affiliated Hospital of Kunming Medical University) to explore the effect of aminophylline in sepsis. Patients were assigned in a 1:1 ratio to receive standard treatment with or without aminophylline.

\section{Patient randomization}

All the patients in the ICU with sepsis were screened. Patients were eligible if diagnosed with sepsis in 48 hours ${ }^{7}$ and did not meet any exclusion criteria (see the Methods section in the Supplementary Appendix). All the patients provided written informed consent prior to participating in the study.

We used random numbers in a 1:1 ratio for central randomization, and trial-group assignments were placed in sequentially numbered envelopes, which were distributed to trial sites to be opened at the time of enrollment. Randomization had to be completed within 2 hours after the patients met the inclusion criteria. 
Blinding to study-group assignment was not possible. Patients were stratified according to shock status at screening. Data were recorded on paper case-report forms that were stored in this study on the Data Monitoring Committee.

\section{Study interventions}

After randomization, the usual-care group continued to receive standard therapy as determined by the treating clinicians. The aminophylline group was given aminophylline intravenously based on standard treatment: aminophylline was injected intravenously at $3 \mathrm{mg} / \mathrm{kg}$ for $30 \mathrm{~min}$, before being pumped intravenously at $0.4 \mathrm{mg} \cdot \mathrm{kg}-1 \cdot \mathrm{h}-1$ for 5 days. The aminophylline was provided by the hospital pharmacy and not by the drug manufacturer. At least one trained staff member was available throughout the intervention period.

The day of screening was recorded as day 0 , and patients in the aminophylline group began to receive aminophylline according to the study protocol on day 0 .

\section{Outcome measures}

The primary outcome was all-cause mortality at 28 days. The secondary outcomes included all-cause mortality at 60 days; the scores on the Sequential Organ Failure Assessment (SOFA) on day 0 to day 5; the scores on the APACHE II on day 0 and day 5; mechanical ventilation; length of stay in the hospital and intensive care unit; duration of survival; output urine on day 0 to day $5 ; 24$-hour fluid intake on day 0 to day 5; oxygenation index on day 0 to day 5 ; the blood concentration of aminophylline on day 1 , day 3 , and day 5 ; and assay indexes of routine blood, coagulation function, biochemistry, arterial blood gas analysis, $\mathrm{C}$-reactive protein, procalcitonin (PCT), routine urine on day 0 to day 5 . Adverse events were monitored until 48 hours after the end of treatment.

\section{Statistical analysis}

The primary comparisons of the two groups were tested at a two-sided type I error rate of $5 \%$, without adjustment for multiplicity. Continuous variables were reported as means and standard deviations or medians and interquartile ranges. Categorical variables were reported as proportions. We conducted LOCF (last-observation-carried-forward method) to fill in the missing values. We used the Fisher test or the chi-squared test to compare group differences among the categorical variables. Two-factor analysis of variance (ANOVA) was used. The data conforming to the spherical test were analyzed using a monadic analysis of variance; otherwise, multivariate analysis of variance was used. We used covariance analysis to detect changes in the continuous endpoints of the APACHE II scores between the two groups. Nonrepetitive data were tested using the t-test or Mann-Whitney $U$ rank-sum test. The survival data were analyzed using Kaplan-Meier survival curves, and the difference between the two groups was detected using the log-rank test. We screened the indicators with forward-LR and predicted the risk of death using Cox proportional hazard regression analysis. SPSS software, version 21.0, was used for all the analyses.

\section{Results}




\section{Patients}

From September 27, 2018, to February 12, 2020, we screened 277 patients with sepsis at the two study sites, resulting in the enrollment of 100 patients ( 80 patients in Zhengzhou and 20 patients in Kunming), including 50 patients in the aminophylline group and 50 patients in the usual-care group. In the usualcare group, 4 patients with septic shock were missing repeated measurements ( 2 died and 2 had discharge requests) and were not involved in repeated data ANOVA. We assessed the 4 patients' survival status at 28 days and 60 days (Fig. 1).

The two groups were well-matched at baseline (Table 1). The most common site of infection in the aminophylline and usual-care groups was the lung (58\%,52\%, respectively), and there was no statistical difference between the two groups. The criterion for septic shock was met in 28 patients $(28 / 50,56.0 \%)$ in the aminophylline group and 27 patients $(27 / 50,54.0 \%)$ in the usual-care group, showing no statistical difference. 


\begin{tabular}{|c|c|c|}
\hline Characteristics & $\begin{array}{l}\text { Aminophylline group } \\
(n=100)\end{array}$ & $\begin{array}{l}\text { Usual-care group } \\
(n=100)\end{array}$ \\
\hline Age, median (IQR), y & $51.5(40.0-64.3)$ & $51.5(42.3-60.5)$ \\
\hline Male sex, no. (\%) & $36(72.0 \%)$ & $35(70.0 \%)$ \\
\hline \multicolumn{3}{|l|}{ Underlying disease, no. (\%) } \\
\hline Hypertension & $15(30.0 \%)$ & $11(22.0 \%)$ \\
\hline Coronary heart disease & $3(6.0 \%)$ & $3(6.0 \%)$ \\
\hline Liver disease & $4(8.0 \%)$ & $2(4.0 \%)$ \\
\hline Chronic obstructive pulmonary disease & $3(6.0 \%)$ & $1(2.0 \%)$ \\
\hline Nervous system disease & $5(10.0 \%)$ & $4(8.0 \%)$ \\
\hline Diabetes mellitus & $12(24.0 \%)$ & $7(14.0 \%)$ \\
\hline Trauma & $3(6.0 \%)$ & $2(4.0 \%)$ \\
\hline Tumor & $1(2.0 \%)$ & $4(8.0 \%)$ \\
\hline Other diseases & $9(18.0 \%)$ & $8(16.0 \%)$ \\
\hline \multicolumn{3}{|l|}{ Site of infection, no. (\%) } \\
\hline Lungs & $29(58.0 \%)$ & $26(52.0 \%)$ \\
\hline Abdomen & $16(32.0 \%)$ & $16(32.0 \%)$ \\
\hline Urogenital tract & $5(10.0 \%)$ & $4(8.0 \%)$ \\
\hline Blood & $10(20.0 \%)$ & $12(24.0 \%)$ \\
\hline Other sites & $13(26.0 \%)$ & $12(24.0 \%)$ \\
\hline Mechanical ventilation, no. (\%) & $22(44.0 \%)$ & $22(44.0 \%)$ \\
\hline Shock, no. (\%) & $28(56.0 \%)$ & $27(54.0 \%)$ \\
\hline
\end{tabular}

a There were no significant difference between the two groups. IQR denotes interquartile range, CHD denotes coronary heart disease, and COPD denotes chronic obstructive pulmonary disease.

b Underlying diseases were self-reported and assessed by the physician.

\section{Analysis of variance for repeated data}


At the baseline of repeated measurements, patients in the aminophylline group had higher platelet counts and fibrinogen (Table 2). The data for repeated measurements were analyzed by multivariate analysis of variance because they did not conform to the spherical test. The results showed that platelet, fibrinogen, creatinine, total protein, albumin, $\mathrm{PH}, \mathrm{C}$-reactive protein, procalcitonin, SOFA scores, 24-hour fluid intake, oxygenation index, and other indicators improved gradually with the extension of treatment time $(\mathrm{P}<$ 0.05). The groups did not show any statistical significance for each repeated measurement index. There was an interaction between the group and time on the SOFA score, oxygenation index, and vasopressor dose in the shock subgroup. With the extension of treatment time, the aminophylline group showed a greater improvement in SOFA score, oxygenation index, and dose of vasopressors in the shock subgroup than in the usual-care group. The aminophylline group showed a greater 24-hour urine output than the usual-care group, but this difference was not statistically significant (Fig. 2). 
Table 2

Comparison of laboratory and clinical indexes between the two groups

$\begin{array}{lll}\text { Aminophylline group } & \text { Usual-care group } & P \\ (n=50) & (n=50) & \text { Value }\end{array}$

$\begin{array}{llll}\text { Dose of vasopressors, median (IQR), } & 0.05(0.00-0.32) & 0.00(0.00-0.28) & 0.652\end{array}$ $\mu \mathrm{g} / \mathrm{kg} / \mathrm{min}^{\mathrm{a}}$

White blood cell count, median (IQR), $\times 103 / \mu \mathrm{L}$

$12.08(8.79-16.77) \quad 12.82(7.55-18.87) \quad 0.730$

Red blood cell count, median (IQR), $\times 106 /$ $\mu \mathrm{L}$

$3.55(2.85-4.13)$

$3.30(2.74-3.79)$

0.301

Hemoglobin, mean (SD), g/L

103.08 (32.16)

102.14 (26.04)

0.873

Platelet count, median (IQR), $\times 103 / \mu \mathrm{L}$

158.50 (86.25-

242.75)

$112.50(28.50-$

$213.50)$

Prothrombin time, median (IQR), sec

$13.40(11.48-15.15)$

$14.25(11.78-15.73)$

0.274

Activated partial thromboplastin time, median (IQR), sec

$31.20(28.10-40.30)$

$33.40(28.28-41.70) \quad 0.539$

Fibrinogen, median (IQR), g/L

$4.59(3.26-6.92)$

$3.65(2.67-4.99)$

0.037

D-Dimer, median, (IQR), mg/L

$1.94(0.85-3.28)$

$2.36(1.05-3.95)$

0.282

Blood urea nitrogen, median, (IQR), $\mathrm{mmol} / \mathrm{L}$

$8.64(5.11-15.67)$

$10.00(5.07-18.89)$

0.725

Serum creatinine, median, (IQR), $\mu \mathrm{mol} / \mathrm{L}$

$79.00(58.98-$

154.03)

$79.75(53.75-149.00 \quad 0.992$

76.75 (43.46-

105.79)

$81.88(42.51-108.36$

0.942 $\mathrm{ml} / \mathrm{min}$

Alanine aminotransferase, median, (IQR), $\mathrm{U} / \mathrm{L}$

$25.50(11.75-76.75)$

$35.85(21.75-63.50)$

0.197

Aspartate aminotransferase, median, (IQR), U/L

$32.50(22.75-76.75)$

$40.50(19.53-97.25)$

0.588

Total protein, median, (IQR), g/L

$56.80(50.65-62.20)$

$56.40(46.33-62.75)$

0.754

Albumin protein, median, (IQR), g/L

$25.55(22.95-31.58)$

$25.75(21.50-30.90)$

0.756

Total bilirubin, median, (IQR), $\mu \mathrm{mol} / \mathrm{L}$

$16.25(8.18-29.15)$

$14.45(10.65-35.90)$

0.408

Direct bilirubin, median, (IQR), $\mu \mathrm{mol} / \mathrm{L}$

$8.20(4.65-16.28)$

$8.95(5.28-27.78)$

0.224

Indirect bilirubin, median, (IQR), $\mu \mathrm{mol} / \mathrm{L}$

$4.80(3.03-10.18)$

$6.25(3.20-10.58)$

0.414

$\mathrm{pH}$ value, median, (IQR)

$7.42(7.36-7.46)$

$7.41(7.36-7.46)$

0.664

a: The only vasopressor used in shock patients at the two centers was noradrenaline. 


\begin{tabular}{|c|c|c|c|}
\hline & $\begin{array}{l}\text { Aminophylline group } \\
(n=50)\end{array}$ & $\begin{array}{l}\text { Usual-care group } \\
(n=50)\end{array}$ & $\begin{array}{l}P \\
\text { Value }\end{array}$ \\
\hline Blood lactate, median, (IQR), mmol/L & $1.50(1.10-2.23)$ & $1.60(1.10-2.83)$ & 0.617 \\
\hline C-reactive protein, median, (IQR), mg/L & $\begin{array}{l}156.91(104.07- \\
236.40)\end{array}$ & $\begin{array}{l}136.25(73.50- \\
217.19)\end{array}$ & 0.343 \\
\hline Procalcitonin, median, (IQR), ng/mL & $7.77(1.04-18.65)$ & $3.03(0.88-13.70)$ & 0.212 \\
\hline Urine specific gravity, median, (IQR) & $1.02(1.02-1.02)$ & $1.02(1.01-1.02)$ & 0.157 \\
\hline 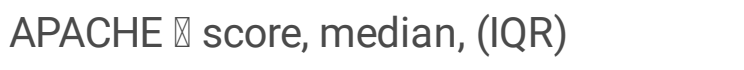 & $17.00(11.75-21.00)$ & $14.00(11.00-20.00)$ & 0.165 \\
\hline SOFA score, median, (IQR) & $8.00(6.00-11.00)$ & $8.00(5.00-11.25)$ & 0.906 \\
\hline 24-hour liquid intake, median, (IQR), ml & $\begin{array}{l}4238.00(3178.00- \\
5371.50)\end{array}$ & $\begin{array}{l}4052.00(3259.00- \\
5308.00)\end{array}$ & 0.777 \\
\hline 24-hour urine output, median, (IQR), ml & $\begin{array}{l}2380.00(1714.29- \\
4066.07)\end{array}$ & $\begin{array}{l}2950.00(1440.00- \\
4065.00)\end{array}$ & 0.989 \\
\hline Oxygenation index, median, (IQR) & $\begin{array}{l}211.00(170.75- \\
274.98)\end{array}$ & $\begin{array}{l}249.50(172.25- \\
305.25)\end{array}$ & 0.190 \\
\hline
\end{tabular}

\section{Mortality}

A total of 23 patients died on the 28th day, including $20(20 / 55)$ in the shock subgroup. The mortality of the aminophylline group was lower than that of the usual-care group (28-day mortality rate, $14.0 \mathrm{vs.}$ $32.0 \%$; 60 -day mortality rate, 16.0 vs. $36.0 \%$ ). In the shock subgroup, the 28 -day and 60 -day mortality of the aminophylline group were significantly lower than those of the control group (28-day mortality rate, 25.0 vs. $48.2 \%$; 60 -day mortality rate, 28.6 vs. $51.9 \%$ ), but there was no statistical difference between the two groups (Fig. 3).

\section{Survival analysis}

The survival benefits seen in the aminophylline group were better than in the usual-care group. There was a significant difference in the duration of survival between the two groups $(P=0.039$ by the log-rank test) (Fig. 4).

The COX proportional-hazards model adjusted imbalance baseline (platelet count and fibrinogen) showed the following: group $(\mathrm{HR}=0.312,95 \% \mathrm{Cl}$ : $0.129-0.753, \mathrm{P}=0.010)$, shock $(\mathrm{HR}=4.695,95 \% \mathrm{Cl}$ : 1.402-15.722, $P=0.012)$, bloodstream infection ( $H R=3.290,95 \% \mathrm{Cl}: 1.332-8.126, P=0.010)$, SOFA score $(\mathrm{HR}=1.180,95 \% \mathrm{Cl}: 1.023-1.360, \mathrm{P}=0.023)$, D-dimer (per $1 \mathrm{mg} / \mathrm{L}, \mathrm{HR}=1.109,95 \% \mathrm{Cl}: 1.034-1.190, \mathrm{P}=$ 0.004 ), and platelet count (per $10 \times 10^{3} / \mu \mathrm{L}, \mathrm{HR}=1.083,95 \% \mathrm{Cl}: 1.033-1.136, \mathrm{P}=0.001$ ) were all independent risk factors for death events. 
Further bivariate correlation analysis showed that the platelet count on day 0 was positively correlated with survival time (correlation coefficient $=0.025, \mathrm{P}=0.807$ ) and mortality risk (correlation coefficient $=$ $0.059, \mathrm{P}=0.475$ ), but the association was not statistically significant. The change in platelet count on day 5 was positively correlated with survival time (correlation coefficient $=0.284, P=0.005$ ) and negatively correlated with risk of death (correlation coefficient $=-0.279, P=0.001$ ); the association was statistically significant.

\section{Other secondary outcomes}

The length of stay in the hospital and ICU were similar in the two groups, and the difference was not statistically significant. In the aminophylline group, the median length of stay in the hospital and ICU were 18.50 days $(11.75,31.25)$ and 10.00 days $(7.00,16.00)$, respectively. In the usual-care group, the median length of stay in the hospital and ICU were 18.50 days $(11.75,31.25)$ and 10.00 days $(7.00,16.00)$, respectively. In the shock subgroup, the median length of stay in the hospital and ICU were 16.50 days $(9.50,28.75)$ and 9.00 days $(7.00,13.75)$, respectively, in the aminophylline group, and 17.00 days $(9.00$, $23.00)$ and 9.00 days $(7.00,16.00)$, respectively, in the usual-care group, showing no statistical significance in two groups.

According to the adjusted baseline APACHE II scores on day 0 , the APACHE II scores on day 5 in the aminophylline group and usual-care group were 10.79 (95\% Cl: 9.20-12.38) and 12.84 (95\% Cl: 11.1814.49), respectively. There was no statistically significant difference between the two groups $(P=0.083, F$ $=3.072$, difference $=-2.042,95 \% \mathrm{Cl}:-4.356-0.272$ ). In the shock subgroup, there was also no statistically significant difference in the adjusted APACHE II scores on day 5 between the aminophylline group and usual-care group $(11.21,95 \% \mathrm{Cl}: 8.96-13.45$ vs. $13.58,95 \% \mathrm{Cl}: 11.10-16.06, \mathrm{P}=0.166, \mathrm{~F}=1.974$, difference $=-2.371,95 \% \mathrm{Cl}:-5.763-1.022)$.

\section{Adverse effects}

No aminophylline-related adverse reactions were observed within 48 hours from enrollment to 48 hours afterward. Adverse reactions to aminophylline are closely related to the drug concentration. If the concentration of aminophylline exceeds $15 \mathrm{ug} / \mathrm{ml}$, the risk of mild adverse reactions is increased; when it exceeds $20 \mathrm{ug} / \mathrm{ml}$, tachycardia and other arrhythmias may occur; and over $40 \mathrm{ug} / \mathrm{ml}$, fever, dehydration, convulsions, even cardiac arrest may occur. We monitored the concentrations of aminophylline on days 1 , 3 , and 5 , and these were $6.66 \pm 3.30 \mathrm{ug} / \mathrm{ml}, 8.09 \pm 4.23 \mathrm{ug} / \mathrm{ml}$, and $7.74 \pm 3.67 \mathrm{ug} / \mathrm{ml}$, respectively. The difference in aminophylline concentration at 3-time points was statistically significant $(P=0.024)$ : at day 3 , this was $1.425 \mathrm{ug} / \mathrm{ml}(95 \% \mathrm{Cl}: 0.191-2.659, \mathrm{P}=0.019)$ higher than on day 1 . At day 5 , the difference was $1.077 \mathrm{ug} / \mathrm{ml}(95 \% \mathrm{Cl}:-0.405-2.558)$ higher than on day 1 and not statistically significant $(P=0.233)$. The difference on day 5 was decreased by $0.348 \mathrm{ug} / \mathrm{ml}(95 \% \mathrm{Cl}:-1.575-0.880)$ compared to day 3, with no statistically significant difference $(P=1.000)$.

With the extension of aminophylline application time, the numbers of patients with an aminophylline concentration exceeding $15 \mathrm{ug} / \mathrm{ml}$ increased: one patient on day $1(23.08 \mathrm{ug} / \mathrm{ml}), 3$ patients on day 3 
$(19.60 \mathrm{ug} / \mathrm{ml}, 18.34 \mathrm{ug} / \mathrm{ml}$, and $15.20 \mathrm{ug} / \mathrm{ml})$, and 4 patients on day $5(17.40 \mathrm{ug} / \mathrm{ml}, 15.60 \mathrm{ug} / \mathrm{ml}, 15.20$ $\mathrm{ug} / \mathrm{ml}$, and $15.06 \mathrm{ug} / \mathrm{ml})$.

\section{Discussion}

The results of this study showed that aminophylline was protective against death in patients with sepsis. The 28-day and 60-day mortalities of the aminophylline group were significantly reduced, and the survival time was prolonged. Simultaneously, it promoted the improvement of the SOFA score and oxygenation index of patients with sepsis and the reduction of vasopressors in patients with septic shock.

Pulmonary infection occurred in $55 \%$ of the sepsis patients included in this study (58\% in the aminophylline group and $52 \%$ in the control group). Aminophylline showed no statistically significant difference in the oxygenation index but did demonstrate some interaction with the time factor. With the extension of time, improvement in the oxygenation index of the aminophylline group was more obvious than in the usual-care group. Studies have shown that aminophylline can stimulate respiration, enhance respiratory muscle contractility, increase pulmonary ventilation, and improve the tolerance to hypoxia without increasing oxygenation ${ }^{15,16}$. The effect of aminophylline on the oxygenation index of patients with sepsis is reasonable.

There were 55 patients in the septic shock subgroup, 28 in the aminophylline group, and 27 in the control group. With the extension of time, the dose of vasopressor in the aminophylline group decreased more than in the usual-care group. It has been reported that aminophylline can be effectively used in the treatment of hypotension and bradycardia in paraplegic patients ${ }^{21}$. Together with the results of this study, it is clear that aminophylline has a positive effect on septic shock.

The results of this study showed that the SOFA score of the aminophylline group improved significantly with the extension of treatment time. The SOFA score was used to evaluate the function of multiple organs in sepsis patients. Aminophylline showed an advantage in two of the six indicators (oxygenation index, the doses of vasopressor) in the SOFA score.

The diuretic effect of aminophylline has been widely recognized in the $\operatorname{clinic}^{22-24}$. The aminophylline group also had an advantage in urine volume. We primarily considered that the difference in urine volume was not detected due to insufficient sample size. Studies have shown that a low dose of aminophylline, acting as a non-selective adenosine receptor, can increase renal perfusion and improve urine volume by dilating glomerular renal arterioles ${ }^{20}$. Aminophylline has been shown to reduce the incidence of acute kidney injury after cardiac surgery in children, but this finding remains controversial ${ }^{23,25-27}$. The diuretic effect of aminophylline was more significant in the early stages ${ }^{23}$, similar to the findings in this study.

Cox regression analysis adjusting for baseline imbalance (platelet count on day 0 and fibrinogen) showed that aminophylline was a protective factor and that platelets, shock, bloodstream infection, SOFA score, and D-dimer were independent risk factors. Platelet activation is an important pathophysiological 
mechanism in the development of sepsis. The trend over time, as well as the platelet number, morphology, and function may be used as biomarkers for risk stratification of patients with sepsis. A lower admission platelet count is associated with a higher incidence of septic shock and an increased

mortality rate ${ }^{28,29}$. There was no significant correlation between baseline platelet value and survival time or death event in our study. The change of platelet count on day 5 was positively correlated with survival time and negatively correlated with risk of death, and this association was statistically significant. It remains to be further studied whether platelet count or the trend over time can better reflect the prognosis of patients. The sample size of our study was limited and cannot adequately reflect the real-world situation.

No aminophylline-related adverse reactions were observed from enrollment to 48 hours later. Although aminophylline is widely used in clinical practice, it has a narrow safety margin at regular doses, which is the reason for its limited clinical application. Usually, the effective plasma concentration of aminophylline is about $10 \mathrm{ug} / \mathrm{ml}$. There is an increased risk of adverse reactions when aminophylline concentrations exceed $15 \mathrm{ug} / \mathrm{ml}$.

The results of this study showed that the blood concentration of aminophylline was at a low level but still showed a therapeutic effect. The results also showed that with the extension of the application time of aminophylline, the numbers of patients with an aminophylline concentration over $15 \mathrm{ug} / \mathrm{ml}$ tended to increase, specifically, for one patient, 3 patients, and 4 patients on days 1,3 , and 5 , respectively. Therefore, the monitoring of blood drug concentrations should be enhanced with the application of aminophylline to avoid adverse reactions.

There were limitations in this study. First, there exists no prior study to assist in calculating a reasonable sample size, and the sample size in this study was small. Second, the respiratory system, kidney system, and inflammatory indicators were not completely adequate to reflect the role of aminophylline in these systems.

\section{Conclusions}

Aminophylline can reduce the risk of death in patients with sepsis, showing certain advantages in the respiratory system and circulatory system. The therapeutic effect of aminophylline in sepsis needs to be further verified in large-sample clinical studies.

\section{Abbreviations}

ANOVA

analysis of variance

COPD

chronic obstructive pulmonary disease

ICU 
intensive care unit

LOCF

last-observation-carried-forward method

SOFA

Sequential Organ Failure Assessment

\section{Declarations}

\section{Ethics approval and consent to participate}

This study has been approved by the Scientific Research and Clinical Trial Ethics Committee of the First Affiliated Hospital of Zhengzhou University (Drug-2018-94).

Each patient or their caregiver(s) signed a written informed consent after a comprehensive explanation of the study.

\section{Consent for publication}

Not applicable.

\section{Availability of data and materials}

All data generated or analyzed during this study are included in this published article and its supplementary information files.

\section{Competing interests}

The authors declare that they have no competing interests.

\section{Funding}

This study was supported by the National Natural Science Joint Foundation of China (Grant No. U2004121), Leading Talents Fund in Science and Technology Innovation in Henan Province (Grant No. 194200510017), the "51282" Project Leaders of Scientific and Technological Innovative Talents from the Health and Family Planning Commission in Henan Province (2016-32), and the Science and Technology People-Benefit project of Zhengzhou (2019KJHM0001)

\section{Authors' contributions}

Study design, development, and study setup were conducted by Tongwen Sun, Wangbin Xu, Ruifang Zhang, and Dongmei Dai. Site setup, subject enrolment, data collection, and research governance were performed by Ruifang Zhang, Dongmei Dai, Yan Wang, Xuexiu Shi, Shuguang Zhang, Xiaoguang Duan, Haixu Wang, Yonggang Luo, Shaohua Liu, Bing Han, Xiaojuan Zhang, and Yu Fang. Ruifang Zhang, Huan Liu, and Dong Wang performed the statistical analysis. The initial draft of the manuscript was written by 
Ruifang Zhang, Huan Liu, Dong Wang, and Xianfei Ding. All the authors reviewed and commented on this and subsequent versions of the manuscript. No individual who is not an author participated in the writing or editing of the manuscript.

\section{Acknowledgments}

None.

\section{References}

1. Reinhart K, Daniels R, Kissoon N, Machado FR, Schachter RD, Finfer S. Recognizing Sepsis as a Global Health Priority - A WHO Resolution. The New England journal of medicine. 2017;377(5):414417.

2. Tiru B, DiNino EK, Orenstein A, et al. The Economic and Humanistic Burden of Severe Sepsis. PharmacoEconomics. 2015;33(9):925-937.

3. Adhikari NK, Fowler RA, Bhagwanjee S, Rubenfeld GD. Critical care and the global burden of critical illness in adults. Lancet (London, England). 2010;376(9749):1339-1346.

4. Liu V, Escobar GJ, Greene JD, et al. Hospital deaths in patients with sepsis from 2 independent cohorts. Jama. 2014;312(1):90-92.

5. Vincent JL, Marshall JC, Namendys-Silva SA, et al. Assessment of the worldwide burden of critical illness: the intensive care over nations (ICON) audit. The Lancet. Respiratory medicine. 2014;2(5):380-386.

6. Cecconi M, Evans L, Levy M, Rhodes A. Sepsis and septic shock. Lancet (London, England). 2018;392(10141):75-87.

7. Singer M, Deutschman CS, Seymour CW, et al. The Third International Consensus Definitions for Sepsis and Septic Shock (Sepsis-3). Jama. 2016;315(8):801-810.

8. Bin Y, Xiao Y, Huang D, et al. Theophylline inhibits cigarette smoke-induced inflammation in skeletal muscle by upregulating HDAC2 expression and decreasing NF-KB activation. American journal of physiology. Lung cellular and molecular physiology. 2019;316(1):L197-I205.

9. Ichiyama T, Hasegawa S, Matsubara T, Hayashi T, Furukawa S. Theophylline inhibits NF-kappa B activation and I kappa B alpha degradation in human pulmonary epithelial cells. NaunynSchmiedeberg's archives of pharmacology. 2001;364(6):558-561.

10. Cosio BG, Tsaprouni L, Ito K, Jazrawi E, Adcock IM, Barnes PJ. Theophylline restores histone deacetylase activity and steroid responses in COPD macrophages. The Journal of experimental medicine. 2004;200(5):689-695.

11. To Y, Ito K, Kizawa Y, et al. Targeting phosphoinositide-3-kinase-delta with theophylline reverses corticosteroid insensitivity in chronic obstructive pulmonary disease. American journal of respiratory and critical care medicine. 2010;182(7):897-904. 
12. Sullivan P, Bekir S, Jaffar Z, Page C, Jeffery P, Costello J. Anti-inflammatory effects of low-dose oral theophylline in atopic asthma. Lancet (London, England). 1994;343(8904):1006-1008.

13. Lim S, Tomita K, Caramori G, et al. Low-dose theophylline reduces eosinophilic inflammation but not exhaled nitric oxide in mild asthma. American journal of respiratory and critical care medicine. 2001;164(2):273-276.

14. Kraft M, Torvik JA, Trudeau JB, Wenzel SE, Martin RJ. Theophylline: potential antiinflammatory effects in nocturnal asthma. The Journal of allergy and clinical immunology. 1996;97(6):1242-1246.

15. Suneby Jagers JV, Ji M, Rothwell B, Easton PA. Aminophylline increases parasternal muscle action in awake canines. Pulmonary pharmacology \& therapeutics. 2019;56:1-7.

16. Schroeder T, Piantadosi CA, Natoli MJ, Autmizguine J, Cohen-Wolkowieczs M, Hamilton KL. Safety and Ergogenic Properties of Combined Aminophylline and Ambrisentan in Hypoxia. 2018;103(5):888898.

17. Vincent JL, Rello J, Marshall J, et al. International study of the prevalence and outcomes of infection in intensive care units. Jama. 2009;302(21):2323-2329.

18. Vincent JL, Sakr Y, Sprung CL, et al. Sepsis in European intensive care units: results of the SOAP study. Critical care medicine. 2006;34(2):344-353.

19. Karlsson S, Varpula M, Ruokonen E, et al. Incidence, treatment, and outcome of severe sepsis in ICUtreated adults in Finland: the Finnsepsis study. Intensive care medicine. 2007;33(3):435-443.

20. Park K, Trout LC, Xu C, Wang M, Tamburro RF, Halstead ES. No Requirement for Targeted Theophylline Levels for Diuretic Effect of Aminophylline in Critically III Children. Pediatric critical care medicine : a journal of the Society of Critical Care Medicine and the World Federation of Pediatric Intensive and Critical Care Societies. 2018;19(8):e425-e432.

21. Mojtahedzadeh M, Taghvaye-Masoumi H, Najafi A, Dianatkhah M, Sharifnia H, Shahrokhi M. Management of Hypotension and Bradycardia Caused By Spinal Cord Injury. The Usefulness of Midodrine and Methylxanthines. Iranian journal of pharmaceutical research : IJPR. 2019;18(4):21312135.

22. Tamburro RF, Thomas NJ, Ceneviva GD, Dettorre MD, Brummel GL, Lucking SE. A prospective assessment of the effect of aminophylline therapy on urine output and inflammation in critically ill children. Frontiers in pediatrics. 2014;2:59.

23. Onder AM, Rosen D, Mullett C, et al. Comparison of Intraoperative Aminophylline Versus Furosemide in Treatment of Oliguria During Pediatric Cardiac Surgery. Pediatric critical care medicine : a journal of the Society of Critical Care Medicine and the World Federation of Pediatric Intensive and Critical Care Societies. 2016;17(8):753-763.

24. Barnes PJ. Theophylline. American journal of respiratory and critical care medicine. 2013;188(8):901906.

25. McMahon K, Zappitelli M. Aminophylline for Acute Kidney Injury After Pediatric Cardiac Surgery: Finally Entering the Next Phase in Child Acute Kidney Injury Research. Pediatric critical care medicine 
: a journal of the Society of Critical Care Medicine and the World Federation of Pediatric Intensive and Critical Care Societies. 2016;17(2):170-171.

26. Gebhard DJ, Akcan-Arikan A. You Can Teach an Old Drug New Tricks-Aminophylline for Cardiac Surgery-Associated Acute Kidney Injury. Pediatric critical care medicine : a journal of the Society of Critical Care Medicine and the World Federation of Pediatric Intensive and Critical Care Societies. 2016;17(8):798-799.

27. Axelrod DM, Sutherland SM, Anglemyer A, Grimm PC, Roth SJ. A Double-Blinded, Randomized, Placebo-Controlled Clinical Trial of Aminophylline to Prevent Acute Kidney Injury in Children Following Congenital Heart Surgery With Cardiopulmonary Bypass. Pediatric critical care medicine: a journal of the Society of Critical Care Medicine and the World Federation of Pediatric Intensive and Critical Care Societies. 2016;17(2):135-143.

28. Brogly N, Devos P, Boussekey N, Georges H, Chiche A, Leroy O. Impact of thrombocytopenia on outcome of patients admitted to ICU for severe community-acquired pneumonia. The Journal of infection. 2007;55(2):136-140.

29. Pigozzi L, Aron JP, Ball J, Cecconi M. Understanding platelet dysfunction in sepsis. Intensive care medicine. 2016;42(4):583-586.

\section{Figures}




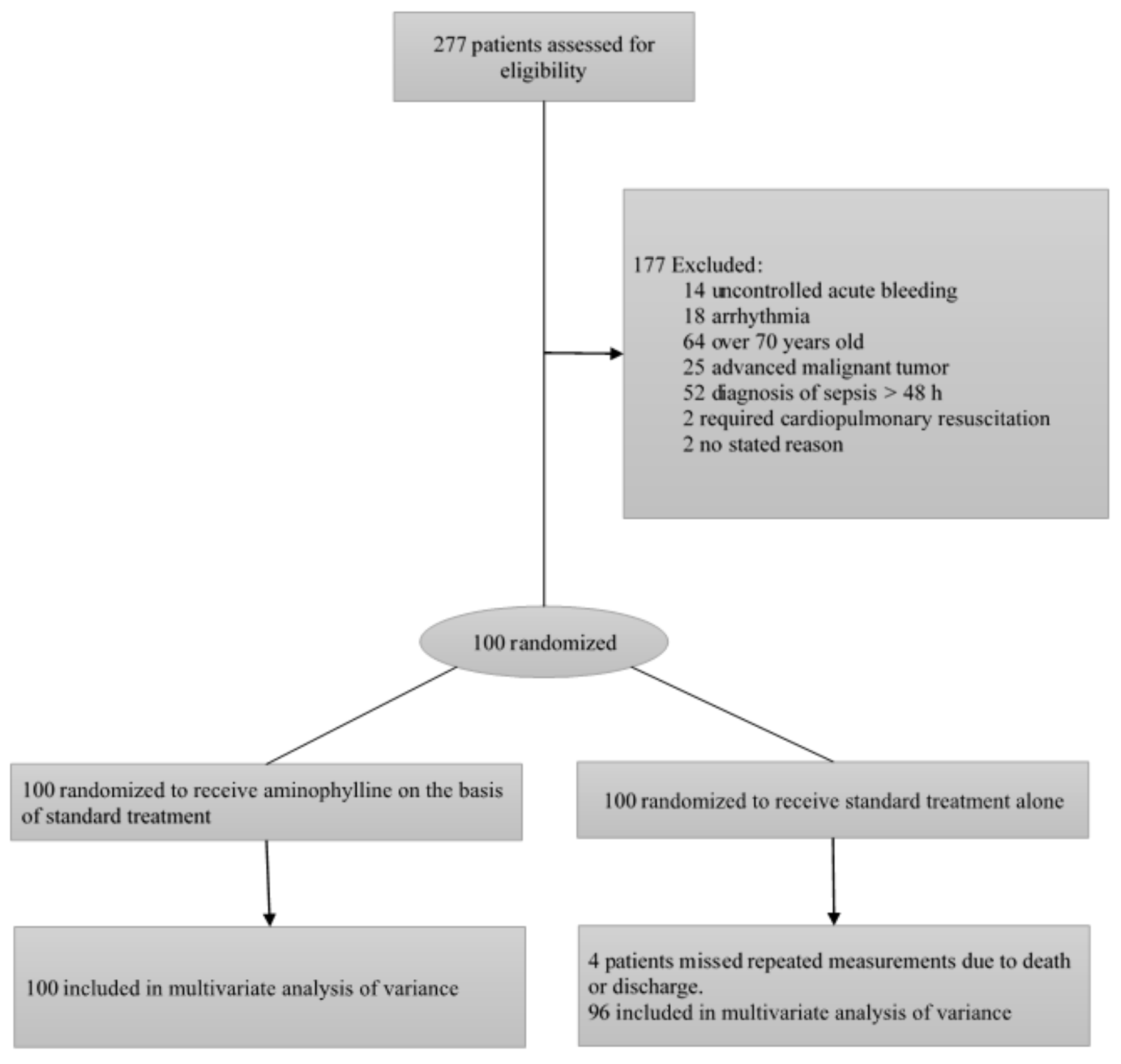

Figure 1

Flow of Patients in Trial 

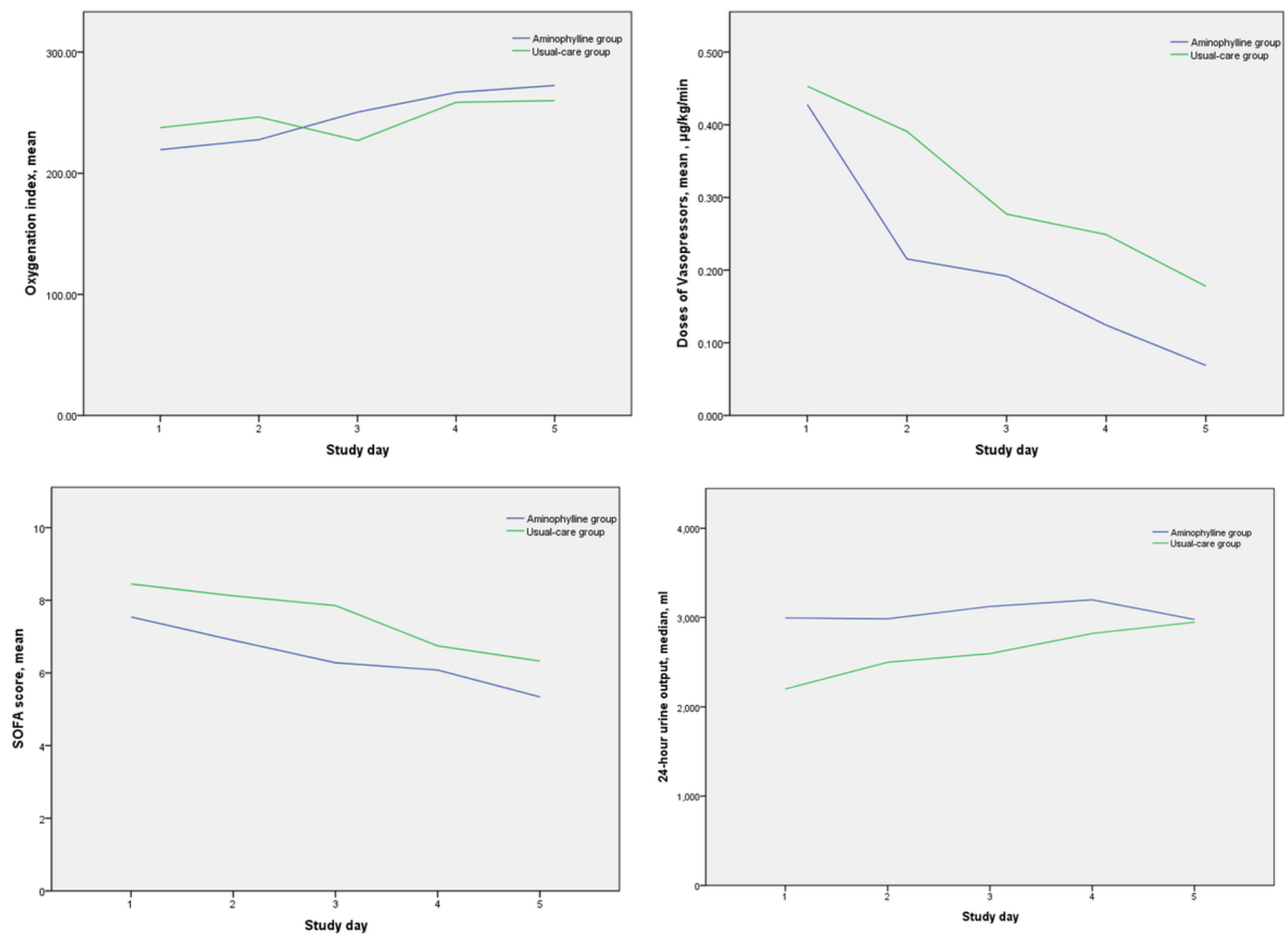

Figure 2

Changes in oxygenation index, doses of pressors, SOFA score and urine volume in both groups over five days 


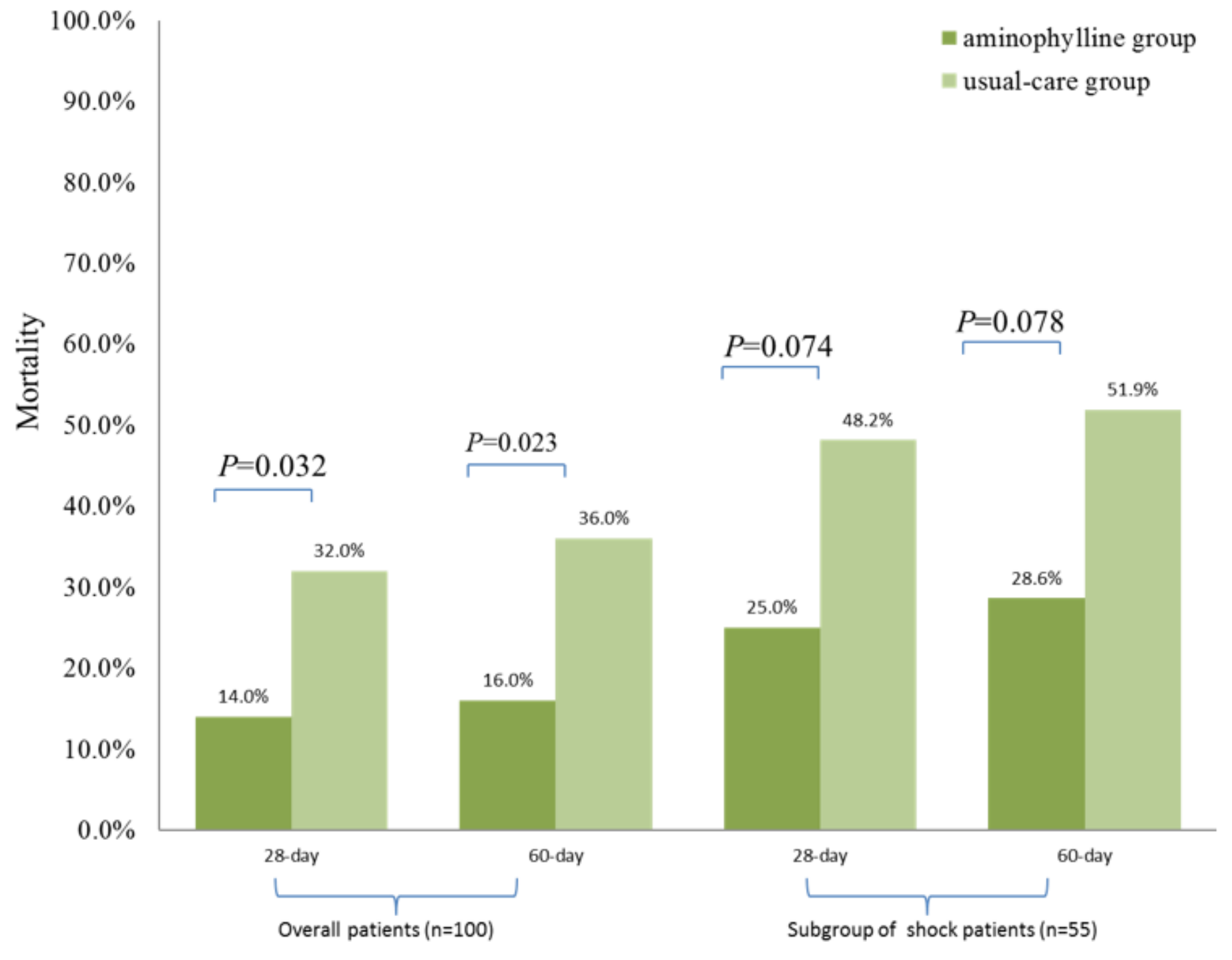

Figure 3

Comparison of mortality rates between the two groups 


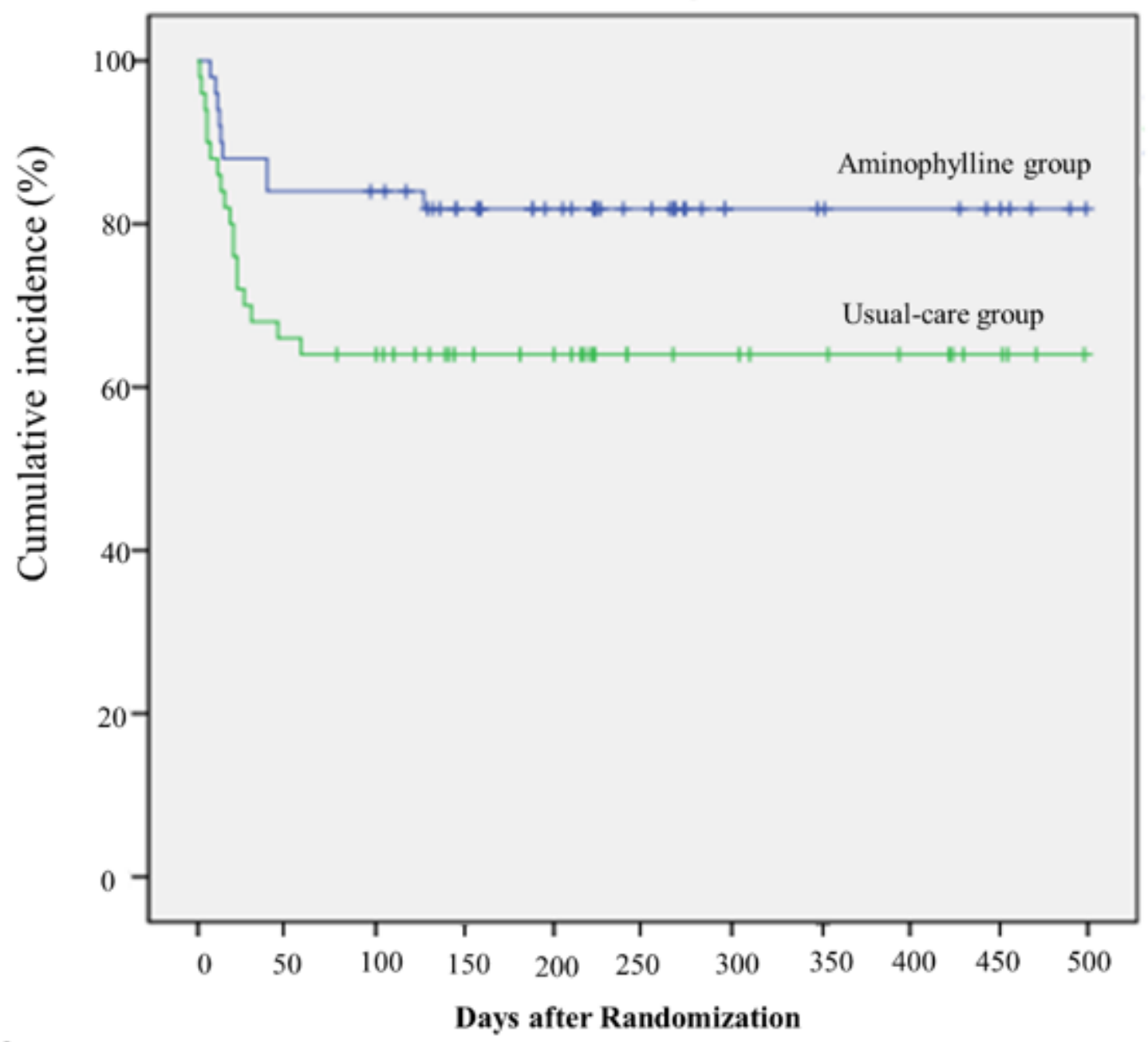

No. at Risk

Aminophylline group

$\begin{array}{llll}50 & 42 & 41 & 33\end{array}$

$27 \quad 19$

Usual-care group

$33 \quad 30 \quad 23$

$23 \quad 20$

$20 \quad 12$

\section{Figure 4}

Kaplan-Meier Analysis by Randomization Group 